\title{
LA DEFINICIÓN DE LAS TRAYECTORIAS LITERARIAS EN DOS ESCRITORAS CHILENAS MODERNAS: MARÍA FLORA YÁÑEZ Y MARTA BRUNET ${ }^{1}$
}

\author{
Natalia Cisterna \\ Universidad de Chile \\ natacisterna@gmail.com
}

RESUMEN / ABSTRACT

El artículo se propone analizar la configuración de la trayectoria literaria en dos escritoras chilenas modernas, María Flora Yáñez y Marta Brunet, considerando que sus distintas inserciones en el campo cultural de su época están determinadas por sus respectivos orígenes sociales y las normas de género sexual. María Flora Yáñez y Marta Brunet son parte de una generación de autoras profesionales que entienden su ejercicio escritural como una actividad pública, reconociendo en ella características propias, distintas a otras prácticas discursivas y que debe ser perfeccionada a través del tiempo a partir de una labor permanente de lectura, escritura y divulgación de sus obras. Para las mujeres, sin embargo, la profesionalización se experimentó con dificultades producto de la persistencia de discursos que limitaban su ingreso en las esferas públicas $\mathrm{y}$, por tanto, culturales. El silencio letrado al que históricamente ha sido sometido el género femenino impulsó el surgimiento de voces críticas que leían con desconfianza o

1 Este artículo se inserta en el marco de los siguientes proyectos de investigación: Fondecyt $N^{\circ}$ 11121340: "Ficcionalizar y pensar la cultura: análisis a las reflexiones sobre los campos culturales y modelos literarios en la narrativa de autoras latinoamericanas de la primera mitad del siglo XX", Natalia Cisterna (Investigadora responsable). Proyecto Fondecyt $N^{\circ}$ 1110108: "Ficción y gestión: trayectorias de mujeres escritoras en el campo cultural chileno en la primera mitad del siglo XX", Darcie Doll (Investigadora responsable). Asimismo, agradezco a la Vicerrectoría de Investigación y Desarrollo de la Universidad de Chile que, a través de la Beca de Ayuda de Viaje, me permitió presentar en el 54 Congreso Internacional de Americanistas (ICA), realizado en Viena el 2012, la versión preliminar de este trabajo bajo el título: "Pensando el lugar de la escritura femenina chilena en la primera mitad del siglo XX". 
rechazo el trabajo de las autoras modernas, lo que las obligó a definir trayectorias literarias a partir de distintas estrategias que posibilitarán su reconocimiento en los campos culturales. Estas estrategias dieron lugar a un campo profesional femenino heterogéneo, en donde el habitus de clase social y las normas de género jugaron un papel fundamental al configurar sus particulares relaciones con el campo cultural y, en definitiva, sus trayectorias.

PALABRAS ClAVE: literatura de mujeres, campo cultural chileno, trayectorias literarias.

The article has as its object to analyze the configuration of the literary trajectory of two Chilean modern writers, María Flora Yáñez and Marta Brunet, considering that their different insertions in the cultural field in that time are determined by their social origins, and gender norms. Both María Flora Yáñez and Marta Brunet are part of a generation of professional authors that understand their writing as a public activity, recognizing in this action its own characteristics, different from other speech practices, and as an activity that has to be perfected throughout time with permanent reading, writing and divulging tasks. For women, however, this professionalization was experimented with difficulties because of the persistence of discourses that limited women's entering in the public and cultural spheres. The literate silence to which the female gender has been historically submitted gave place to the arousal of critical voices that red with mistrust or rejection the work of these modern female authors, which force them to define literary trajectories from different strategies that will allow them to be recognized in the cultural fields. These strategies gave place to a heterogeneous professional field, in which social class habitus and gender norms played a fundamental role by configuring their particular relations with the cultural field, and ultimately, their trajectories.

KEY WORDS: Women's literature, chilean cultural field.

\section{LA VISIBILIZACIÓN FEMENINA EN EL SILENCIO LETRADO}

En 1917, la escritora chilena Luisa Zanelli publicó Mujeres chilenas de letras. El trabajo de Zanelli tenía como fin dar cuenta de la presencia femenina en el ámbito público desde la Colonia hasta inicios del siglo XX. El libro era ambicioso, no solo por el extenso marco histórico que abarcaba, sino porque su criterio de selección era amplio. La autora entendía el ejercicio letrado como todo tipo de actividad pública de carácter profesional y/o ilustrada. Mujeres chilenas de letras se transformó, así, en la primera compilación que exponía una gran variedad de actividades y nombres: desde la titulación de anónimas maestras y jóvenes profesionales del área de la salud, hasta la premiación de Gabriela Mistral en los Juegos Florales de 1914 y la actividad intelectual de Amanda Labarca.

El libro de Zanelli es interesante porque se inserta en un contexto especial en el desarrollo de la escritura de mujeres latinoamericanas. Es durante este 
periodo en el que tiene lugar la modernización de la literatura femenina con el surgimiento de la escritora profesional, en el contexto de un proceso de profesionalización general en el ámbito de las letras, que empujó a los literatos a diferenciar su labor de otras prácticas discursivas y a desarrollar sus propuestas estéticas a partir de un trabajo literario permanente. En el siglo XIX, las mujeres dedicadas al quehacer literario eran casos aislados y sus prácticas artísticas se presentaban como actividades accesorias a sus roles asistenciales en la esfera privada. La literatura no constituía una labor que les demandara un perfeccionamiento continuo a través de los años. El siglo $\mathrm{XX}$, en cambio, ve emerger un número importante de escritoras que entienden su trabajo literario como parte relevante de su desarrollo personal e intelectual y, en cuanto tal, le dedicarán mayor tiempo y atención que sus predecesoras. La profesionalización del quehacer literario femenino estuvo sujeta a un posicionamiento activo de las escritoras en sus campos culturales e intelectuales. Este posicionamiento se focalizó en, al menos, tres objetivos: publicar, adquirir formación artística e intelectual y alcanzar reconocimiento entre sus pares, la crítica y el público. Al respecto, Darcie Doll define a las autoras que escriben en este periodo como autoras modernas, describiéndolas en los siguientes términos:

Ya no serán las damas de la elite obligadas a desplazarse por los salones de la casa y en los círculos reducidos de sus amistades ilustradas. El reconocimiento y legitimación correrá por la vía de la escritura 'literaria' y sus actividades culturales o de gestión se orientarán, en forma creciente aunque no exclusiva, hacia actividades más formalizadas y en pos de la inserción en el campo literario como 'escritoras', 'poetas' y/o 'intelectuales' (“Escritoras chilenas de la primera mitad del siglo XX...”).

Si bien Mujeres de letras buscaba exponer la prolífica actividad pública de las mujeres en las dos primeras décadas del siglo, no recoge en sus páginas los procesos de profesionalización a partir de ejercicios autónomos de las disciplinas que empiezan a ser una realidad en aquellos años. En efecto, la ausencia de una clasificación disciplinaria y la agrupación sin distinción de todo tipo de prácticas públicas y nombres configura un catálogo general de rasgos decimonónicos en donde la labor letrada carece de fronteras precisas. Utilizando las reflexiones de Raymond Williams (1980) en relación con las transformaciones de las culturas, el libro de Zanelli revela la presencia de elementos residuales, es decir, formas que comprenden una concepción 
cultural previa a las innovaciones modernas que desde fines del siglo XIX alteran los campos intelectuales y creativos latinoamericanos.

La persistencia de visiones culturales de carácter residual en los discursos puede no parecer tan inusual a inicios de siglo XX. Por aquellos años los cambios modernos convivían con visiones tradicionales. Sin embargo, es posible observar nuevamente este tipo de perspectiva residual con posterioridad al trabajo de Zanelli. En la década del treinta, una de las publicaciones más importantes de la época, orientada fundamentalmente al mundo femenino, la revista Familia, se presentaba como un verdadero mural de contenidos destinados a la nueva mujer, aquella que podía combinar efectivamente sus labores de ama de casa y esposa con su interés por temas culturales y sociales. Una de las secciones más importantes de esta revista era el "Noticiero Femenino". En esta sección se presentaban todo tipo de actividades llevadas a cabo por mujeres: publicaciones y conferencias de figuras destacadas del ámbito cultural, premiaciones a maestras por su labor docente, anuncio de recitales poéticos de señoritas y actividades de beneficencia de agrupaciones femeninas. Para "Noticiero femenino" todo lo relacionado con la presencia de la mujer en actividades públicas merecía ser resaltado. Si bien el carácter misceláneo de la publicación favorecía tal heterogeneidad, esto no explicaba la ausencia de criterios de selección que permitieran destacar las actividades y las mujeres más relevantes o con mayor proyección. En esta sección de Familia, una crítica a una novela de María Flora Yáñez podía convivir perfectamente con la noticia que daba cuenta de una graduación de alumnas de secundaria.

Estas estructuras de catálogo general que se manifiestan en Mujeres chilenas de letras y en "Noticiero Femenino" de Familia, son indicios de una particular forma de enfrentar la escena letrada chilena de aquellos años por parte de las autoras. Más allá del interés propiamente moderno de clasificar las prácticas y discriminar cualitativamente a las escritoras, Zanelli y la editora de Familia (por aquellos años Marta Brunet) estaban impulsadas por una urgencia mayor, visibilizar lo que hasta ese momento era obviado por los discursos públicos: el trabajo intelectual, creativo, político y profesional de las chilenas. En un contexto de un mayor protagonismo de las mujeres en las esferas ciudadanas y de la proliferación de voces conservadoras que se oponían a esta participación femenina, tanto Mujeres chilenas de letras como Familia construyen un mapa global de la presencia de las mujeres en las esferas colectivas; un mapa que le da un lugar a la escritura de mujeres y, al mismo tiempo, la justifica. En efecto, en medio de la cascada de conferencias de autoras, premiaciones literarias, graduaciones de profesionales, invitaciones 
al extranjero y nombramientos oficiales de un sinfín de mujeres, Gabriela Mistral, Amanda Labarca, Marta Brunet, María Monvel, María Flora Yáñez, Inés Echeverría (Iris), entre otras, no parecían seres excepcionales, sino figuras públicas cuya importancia y trabajo se explicaban en un escenario de intensa labor cultural y política de sus pares de género.

Esta necesidad de visibilizar las prácticas femeninas en la esfera pública apunta a la paradójica inserción de la mujer en los campos culturales de su época. Como nunca antes en la historia, las autoras vieron multiplicadas sus posibilidades de publicar y ser acogidas en el ámbito cultural. Sin embargo, los prejuicios sobre las reales capacidades literarias e intelectuales de las mismas primaban en las esferas letradas eminentemente masculinas, lo que impedía que muchas de ellas alcanzaran el reconocimiento y la legitimación artística. En general, a lo largo de la primera mitad del siglo XX, las escritoras se enfrentaron a un campo cultural hostil, que les imponía más barreras para su ingreso que a los varones. Al respecto, Lea Fletcher (2004), en su estudio sobre las escritoras argentinas de los primeros años del siglo XX, expone el conjunto de estrategias que usaron las autoras para poder encontrar un cierto grado de reconocimiento en un medio cultural que en muchos aspectos restringía su ingreso. Solicitudes de prólogos a varones destacados, utilización de seudónimos masculinos, epígrafes o dedicatorias en donde se hacía mención a una figura masculina prominente de la esfera letrada eran mecanismos que permitían a las mujeres abrir algunas puertas en la escena letrada.

En el marco de lo anterior, Adriana Valdés plantea la necesidad de leer las obras de mujeres considerando la tradición letrada en la que se insertan, esto es, teniendo en cuenta los obstáculos que han encontrado las autoras y sus efectos en la escritura de las mismas. En palabras de la autora, "la tradición literaria es el lugar en que se juega la suerte de un texto" (103). Esto implica, también, visualizar cómo las autoras intentaron lidiar con un destino crítico que las condenaba al silencio, que aparecía "como su lugar natural" (103). Leer la escritura de mujeres implica, en parte, observar mecanismos y tácticas de inserción cultural.

Considerando lo expuesto, el propósito de este artículo es rastrear las formas cómo algunas autoras chilenas de las primeras décadas del siglo XX se hacían cargo de su ejercicio letrado, cómo rompían el silencio que pesaba sobre su trabajo y de qué manera asumían la profesionalización al construir su propia trayectoria literaria. Para este análisis me focalizaré en autoras que empiezan a publicar desde 1918 en adelante y que como señalábamos más arriba, Darcie Doll denomina modernas: 
Las llamamos 'modernas', evidentemente, no por aludir a un déficit de modernidad en las otras escritoras, sino, especialmente, porque ellas asumen la escritura ya no como parte de otras actividades, sino con un mayor grado de especialización, lo que funciona en consonancia con un campo literario claramente consolidado ("Escritoras chilenas de la primera mitad del siglo XX...”).

Para Doll, las autoras modernas chilenas desarrollan su trabajo en un campo literario consolidado. Siguiendo las reflexiones de Bourdieu sobre los campos culturales, las autoras modernas se debieron integrar a un espacio social de relativa autonomía de los campos de poder, sostenido en un sistema de relaciones propio y articulado en distintas instancias de legitimación artística e intelectual. El campo cultural, en las teorizaciones de Bourdieu, aparece como un territorio dinámico, en el que los autores en general se incorporan a partir de lógicas de competencias, con el objetivo de alcanzar el reconocimiento. Para este fin, despliegan determinadas trayectorias asumiendo ciertas estrategias o tomas de posición, las que dependerán del lugar que cada uno ocupa en la estructura del campo. Un aspecto importante que posibilitará entender a las autoras modernas es el concepto de trayectoria que propone Bourdieu. Al respecto el autor sostiene que: "Toda trayectoria social debe ser comprendida como una manera singular de recorrer el espacio social, donde se expresan las disposiciones del habitus" (Las reglas del arte... 384).

La trayectoria que despliega, entonces, un autor responde a una decisión personal, una suma de opciones artísticas e intelectuales que va tomando el escritor a lo largo de su vida productiva, pero también esas opciones dependen del habitus de cada autor. En otras palabras, de los principios culturales y valóricos que definen al sujeto. En tal sentido, la trayectoria que traza un autor tiene también una dimensión colectiva: la familia, la escuela, la clase social determinarán el habitus del escritor y su posición en el campo cultural. Asimismo, el habitus nunca es fijo: los distintos posicionamientos en la historia vital de un escritor le permitirán adquirir nuevos capitales culturales y simbólicos, y desechar o transformar los ya incorporados.

Siguiendo esta reflexión, para abordar las trayectorias de las autoras chilenas de inicios de siglo XX debemos tener en cuenta los principios culturales y sociales que definen sus habitus. Ahora bien, en el caso de las autoras, estos principios modeladores que les permiten leer y sentir su mundo responden no solo a sus orígenes sociales sino también a su género sexual. Son las normas de género las que han modelado sus comportamientos, lenguajes, las que 
han delimitado su posición en el conjunto social y las que han dispuesto su silencio letrado.

En tal sentido, la tesis que orienta este análisis sostiene que las autoras chilenas modernas tuvieron relaciones disímiles con su campo letrado, que estas relaciones estaban sujetas a sus distintos orígenes sociales y sobre todo a su género sexual. Por tanto, las particulares formas como cada una de ellas asumió su trabajo intelectual y artístico dio lugar a una generación profesional femenina de carácter heterogéneo. En efecto, no todas desarrollaron trayectorias en las que primaba su trabajo literario e intelectual, muchas de ellas se vieron obligadas a hacer coincidir su labor de creadoras con tareas asociadas a su género sexual que les demandaba su medio social. El grado de autonomía en el ejercicio letrado que logra alcanzar cada una de ellas estará además vinculado a su origen de clase y a sus necesidades materiales y económicas. Para dar cuenta de lo anterior, me centraré en dos autoras modernas, las que desde mi punto de vista constituyen distintas trayectorias letradas, determinadas por sus diferentes orígenes sociales y los modos diversos como asumen las normas de género. Las autoras son María Flora Yáñez (1898-1982) y Marta Brunet (1897-1967).

\section{MARÍA FLORA YÁÑEZ Y LA FUERZA DEL HABITUS}

María Flora Yáñez se inicia en el mundo de las letras tardíamente, a los 42 años (Amaro 86). Hija de Eliodoro Yáñez, y perteneciente a una de las familias más emblemáticas del establishment político y cultural criollo, desde temprano tuvo acceso a una vasta formación en letras clásicas y un estrecho contacto con las esferas y figuras destacadas del quehacer intelectual y artístico nacional. Su temprano vínculo con este mundo, sin embargo, no le garantizó la entrada al mismo, a pesar que desde sus inicios manifestó su inclinación por el quehacer cultural. A diferencia de su hermano, Juan Emar, que en su juventud empieza a expresar distancia de las pautas sociales y de los caminos obvios trazados para los varones de su clase (Amaro 101), María Flora Yáñez construye una existencia apegada a las normas que se le imponen. Hija, esposa y madre dedicada, sus sueños e intereses personales son constantemente desplazados de su proyecto de vida. En su libro Historia de mi vida (1980) describe de este modo el momento en el que decide dar un giro a su existencia: 
Sin el año 1931 yo nunca habría escrito para el público, nunca habría realizado obra. Cuántos esfuerzos hice, vanamente, para encontrarme a mí misma, para cumplir de algún modo mi misión (me refiero a la misión artística). Todo parecía alejarme de ella. Perdía energía estaba desorientada y mi alma se hacía trizas. 'Algún día tendré que ser yo misma', me decía. Pero el camino estaba cerrado. Vino de pronto el sacudimiento. Fue como si brazos invisibles me sacaran de mi inercia para posarme en un clima que a veces creí irreal (246).

Como señala María Flora Yáñez, su camino personal, orientado a la creación literaria, estaba cerrado. Pero ¿cuáles eran los obstáculos que encontraba si a diferencia de muchos otros varones y mujeres de su época contaba con los capitales económicos y culturales suficientes para iniciarse en el mundo de las letras? Los obstáculos estaban precisamente en su habitus de clase y de género sexual (Amaro 100). María Flora Yáñez pertenecía a un círculo social en donde las normas de género femenino estaban claramente definidas en cuanto a los roles y a los espacios a ocupar. La sanción para una mujer que escapaba a estas normas podía ir desde el exilio total de las redes de protección familiar y social (como fue el caso de Teresa Wilms Montt) hasta el desprestigio en los salones de la elite criolla (lo que de un modo u otro experimentó Inés Echeverría). Y si el temor de una sanción social no era suficiente, siempre estaba el peso de las costumbres, de las responsabilidades, de un "deber ser" que se imponía como algo ineludible, un destino que se debía cumplir sin más. En su autobiografía, María Flora Yáñez no se ve atravesada por miedos al "qué dirán": ella escoge casarse joven con un hombre de su misma condición social, tener hijos, destinar su tiempo y su vida a cumplir su rol asistencial con su padre, esposo e hijos. Seguirlos y cuidarlos y abandonar su propio desarrollo artístico. El peso del habitus la determina a tal punto que en su horizonte no se observan ni la ansiedad por el deseo prohibido ni la angustia por un posible enjuiciamiento social. Es por ello que en su autobiografía no son las obligaciones domésticas las responsables directas de su descuido en su formación y desarrollo autorial. Su compromiso familiar y su rol de madre y esposa no son opciones y, por tanto, no se problematizan. Para la escritora es ella la que ha errado: "Me equivoqué de camino" se titula el apartado en donde expone el momento que descubre tardíamente su vocación literaria. Es ella la que no supo ver a tiempo su "misión" o mejor dicho su otra misión: "me refiero a la misión artística". La autora entiende su labor de escritora como una misión nueva, no una misión que viene a desplazar o desestabilizar su vida familiar, sino 
que la complementa. Así, para María Flora Yáñez ser una escritora no significa romper con su habitus, sino amoldar su vida intelectual a él. En otros términos, ella transforma su decisión de convertirse en escritora en un destino, un camino vital que, al igual que sus roles de género de una clase social, es indiscutible. Acá, como en su vida tradicional, no hay opciones, sino misiones y ellas definen su identidad.

Beatriz Sarlo, en uno de los trabajos más interesantes sobre Victoria Ocampo, da cuenta de cómo ésta define su trayectoria de mujer de letras. Al igual que María Flora Yáñez, Ocampo configura su habitus en el seno de la aristocracia local. Son los salones familiares, los clubes exclusivos, los colegios privados, las poderosas redes sociales de su círculo las que la irán definiendo y entregando un sentido de pertenencia a una clase. Sin embargo, a diferencia de María Flora Yáñez, Ocampo tomará paulatinamente distancia de su grupo social. La razón de esta decisión está paradójicamente impulsada por su propio habitus, su formación cosmopolita le permite acceder a lenguas y culturas diversas, a tener contacto con obras y autores que dejan en ella una marca importante. Así, mientras los miembros de su clase social aspiraban solo a convertirse en coleccionistas vulgares de alta cultura, sin aspirar a entenderla mayormente, Ocampo integra plenamente a su experiencia vital tanto las obras clásicas como las nuevas corrientes artísticas y literarias que se despliegan en las metrópolis y en Latinoamérica. Su ruptura con su clase es, entonces, una ruptura con un modelo de vida oligarca que acumula capital simbólico del mismo modo como acumula ganado y tierras, y que es incapaz de entender el arte y las letras contemporáneas:

Su historia es la de una ruptura lenta, trabajosa, nunca completa, con el chic conservador de la 'gente de mundo', y la firma de un pacto de identidad con la 'gente de letras y de arte'. Elige la nobleza de la toga frente a la nobleza de renta de la que provenía (95).

Para Ocampo, la única forma de ser mujer de letras, de posicionarse en una esfera cultural en donde primará el talento y el buen gusto era apartándose de su clase. Una ruptura, que como bien señala Sarlo, nunca es total y no puede ser de otra manera. Para una mujer, acaudalada, pero mujer al fin, romper absolutamente con su clase social es un suicidio. De este modo, Victoria Ocampo replica su habitus de clase en su esfera letrada y artística. La autora, de acuerdo a lo que nos señala Sarlo, construye una aristocracia cultural, integrada no por la vieja clase social, sino por los talentos únicos que a su juicio estaban dotados de cualidades artísticas especiales. Su teoría 
del gusto, en el ámbito del diseño, da cuenta de esto. Para Ocampo, nos dice Sarlo, el gusto no se aprende, no se incorpora con el tiempo, se nace con él. Ocampo configura, así, un espacio de elegidos, un verdadero espejo de ese mundo de privilegiados de clase que conoció desde su infancia.

María Flora Yáñez no se siente obligada a generar un nivel de ruptura similar al que realiza Ocampo con su habitus. Por el contrario, su tránsito al mundo de las letras no lo experimenta como un conflicto con su clase social. Así, mientras Ocampo construye un mundo que acoge los mejores talentos y logra constituirse en la figura articuladora de la actividad cultural y artística bonaerense, María Flora Yáñez dibujará una trayectoria literaria menos ambiciosa y que tendrá escasos reconocimientos críticos de su campo cultural; una trayectoria que estará sostenida en dos grandes presencias, las mismas que han regido su vida familiar: su padre y su hermano. La investigadora Lorena Amaro apunta precisamente a este aspecto en su construcción autorial:

Padre y hermano no solo le hacen sombra, sino que además, como se ha dicho, obstaculizan sus impulsos, aunque sin anularlos del todo. Yáñez escribe: 'Siempre me aniquila el recuerdo de mi pobre papá. Pero en esto de que yo no siguiera mi vocación se equivocó...' (1980:242); sobre su hermano Juan Emar le es imposible acercarse, menos aún compartir la condición de escritores. Las restricciones que vive María Flora, encapsulada por su condición de mujer de clase alta, no existen para 'Pilo', quien se complace en jugar el papel de hijo (y hermano) rebelde, libre de toda sanción familiar (94).

En su autobiografía, esta tutela simbólica de ambos varones es evidente: su padre, Eliodoro Yáñez y su hermano, Juan Emar serán las figuras que enmarcan el relato. En el primer capítulo: "Presencia y actualidad de Eliodoro Yáñez", se detiene en la vida de su padre, el exitoso abogado y político. Eliodoro Yáñez, destaca su hija, proviene de un origen humilde, que a pesar de su condición social logra escalar posiciones y emparentarse con una de las familias tradicionales de la aristocracia chilena. Hábil litigante, político reconocido y fundador de uno de los periódicos más emblemáticos de la época (La Nación), Eliodoro Yáñez será para su hija el modelo del compromiso y la responsabilidad pública. Por otro lado, para su entorno social, María Flora es la "hija de". En su autobiografía la autora reconoce que la escritora Inés Echeverría, su cuñada, no la valora, apenas nota su presencia y solo le presta atención porque es hija de Eliodoro Yáñez. Para Echeverría, su interlocutor es el patriarca fundador de La Nación y no la jovencita que se 
ha casado con su medio hermano. Bajo esta fuerte impronta paterna, la hija pasa a ser la confidente del progenitor, su consejera, su más férrea defensora y enemiga de los que lo han traicionado. Para María Flora Yáñez, su vida pública, su contacto con la escena letrada y política, se reducen a la vida del padre. No es extraño, entonces, que inicie su autobiografía con un extenso capítulo dedicado a él.

En este rol ancilar, su literatura no podrá ver la luz sino hasta la muerte del padre. La emancipación, sin embargo, no es total. La figura de su hermano paulatinamente empieza a alejarse de su entorno más íntimo, a emerger en el campo literario y a transformarse en lo que ella, de alguna u otra manera, aspira ser: un escritor. El hermano de María Flora Yáñez logra romper con su habitus sin mayores problemas. A diferencia de la escritora, cuyo género sexual obstaculizó la transgresión a las normas de su clase social, el joven Emar se encontró con menos limitaciones para rechazar su futuro político y público, diseñado por Eliodoro Yáñez, y entrar a los círculos de la vanguardia literaria. El penúltimo capítulo del libro, "Mi hermano Juan Emar", está precisamente dedicado a ese ser silencioso, que se aparta de sus afectos y que no comparte con ella ningún tipo de complicidad artística e intelectual. La imagen de Emar callado en un rincón de la casa, sin prestar atención a su presencia, que nos traza María Flora Yáñez, de algún modo grafica esa misma distancia que tendrán con ella los circuitos más modernos de creación artística:

la escritora ingresó tardíamente al ámbito de las letras, cargando consigo la etiqueta de burguesa, y sin lograr insertarse como María Luisa Bombal durante su residencia en Buenos Aires, en los grupos de vanguardia, que por formación e intereses pudieron haber sido más cercanos a ella (Amaro 86).

María Flora Yáñez no rompe con su habitus, tampoco se distanciará de él formando una réplica de su orden social en el espacio letrado, como lo hace Victoria Ocampo. La escritora chilena elige configurar una trayectoria literaria sin desprenderse de nada de su mundo de origen, arrastra su vida cultural al seno mismo de su estructura identitaria sujeta a la autoridad masculina. Es por ello que cuando reconstruye su historia personal y literaria en sus memorias, su vida se despliega escoltada por las dos presencias totalizadoras que abren y cierran el texto: el padre, al que venera y que representa el deber ser en la sociedad, y el hermano, que encarna el gesto iconoclasta del mundo literario no reservado al género femenino. 
Esta opción de no romper con su habitus tendrá consecuencias en su inserción en las esferas literarias. María Flora Yáñez se situará como una eterna visitante en el campo cultural, una turista que recorre espacios exóticos para luego regresar a su nido familiar. Es una extranjera que no logra establecer vínculos permanentes. El encuentro con Neruda y sus amigos en Buenos Aires da cuenta de esto último. En el departamento del entonces cónsul chileno en el país trasandino, la escritora se descoloca frente al comportamiento desinhibido de Alfonsina Storni. Su descripción de ese instante revela su extrañeza e impacto por la distancia entre la poesía de Storni y su comportamiento tan poco elevado para el gusto de la chilena. El cuadro que nos presenta la escritora, en donde se describe a la poeta intentando seducir a un artista mucho más joven, al que le habla vulgaridades, y la pelea final entre Neruda y su esposa delante de los invitados, nos arroja a un escenario decadente e inestable (250-254). María Flora Yáñez se decepciona, pero no se escandaliza al punto de apartarse. La huida no es necesaria, porque ella no se compromete con ese medio. Su posición será la de un testigo lejano que observa sin involucrarse. Al respecto, ciertos pasajes de autobiografía ya revelaban esa actitud de observadora, que es capaz de pasear por territorios distintos a su mundo, pero sin integrarse a los mismos:

Ir a los barrios apartados, escudriñar esas calles modestas y vislumbrar algo de la vida de los seres tan distinta a la nuestra me atrae. Hoy fui por Independencia, parque y río. Me salieron de pronto unos perros bravos. Pero yo marcho con el alma muy lejos, en completa inconciencia del peligro (143).

A diferencia de las sensaciones perturbadoras que le surgen en la escena cultural trasandina, en París, invitada por el Pen Club, María Flora Yáñez parece estar más cómoda. El Pen Club organiza a sus socios una serie de encuentros con personalidades culturales e intelectuales del viejo continente, en un ambiente en donde prima el convencionalismo académico y el trato recatado, con recepciones y encuentros en palacios lujosos, entre ellos Versalles ("Contacto con Europa" 31). En París, la autora se incorpora a los círculos letrados, conversa sobre sus obras, se siente escuchada. En el mundo artístico del Pen Club, María Flora no es una "otra", se reconoce en un habitus cultural que, de alguna manera, se asemeja a las convenciones de su clase social.

El episodio del Pen Club es relatado en detalle en un artículo que aparece en la revista Atenea. Sin embargo, en su autobiografía la escritora dedica solo algunos pasajes a sus actividades artísticas e intelectuales. Llama la 
atención que si bien, tal como ella lo expone, su decisión de convertirse en escritora es uno de los hechos más significativos de su vida, no dedique gran parte del libro a narrar su experiencia en el campo cultural ${ }^{2}$. Escasas son sus impresiones sobre el lanzamiento y la recepción de sus escritos. El único pasaje en el que se lee algo sobre estas materias, dice relación con el éxito alcanzado con su primer libro, El abrazo de la tierra:

1933. Gran éxito literario. Apoteosis. Muchos amigos, innumerables admiradores. Invitaciones sin fin, homenajes inmerecidos, incienso, cartas, flores. Éxito injusto. 'El diario Ilustrado' periódico conservador, se ha portado muy bien. Empezó con una admirable crítica de Manuel Vega, elogiándome sin medida. La crítica apareció coronada por mi retrato. Siguieron otras críticas y otras, en 'El imparcial', etc. No puedo negar que este triunfo me halaga y aleja mis tormentos innatos. Y confieso que el cuerpo me pesa menos que un pétalo (242).

En relación con sus actividades en el campo cultural, una de las más importantes fue la fundación del Pen Club en Chile en 1936. A pesar de la importancia de este hecho y la relevancia que sin duda pudo tener para su figuración en el campo cultural chileno, en su autobiografía, María Flora Yáñez no se detiene mayormente en este evento. Tampoco aborda su trabajo como colaboradora en El Diario Ilustrado o la Revista Atenea, su labor en la edición de Antología del cuento moderno chileno (1958) ni de sus conferencias hechas en Barcelona, Sevilla, Lima, entre otras ciudades. Sin embargo, dedica una parte importante del libro a relatarnos la búsqueda de su hijo en EE.UU., el que había cortado los contactos con la familia después de irse a estudiar. Este silencio en sus memorias es revelador. A través de él la autora nos da cuenta del modo como, al final de sus días, entendió su trayectoria literaria. Lo que ella en un momento definió como una misión, se terminó desplegando como un conjunto de actividades que no constituía el espacio central de su existencia. Su vocación literaria es finalmente asumida parcialmente. María Flora Yáñez no puede alcanzar su propio sueño, simplemente porque el mismo la obligaba a una tarea crítica que no pudo o no quiso realizar: problematizar su habitus de clase y las pautas de su género sexual.

2 Los capítulos en los que se centra en su vivencia como autora en los espacios culturales son fundamentalmente tres de los 18 en los que narra su vida. Estos son: "Me equivoqué de camino", "Una temporada en Buenos Aires" y "Montevideo". 


\section{MARTA BRUNET, LOS DESAFÍOS Y CONSECUENCIAS DE SER UNA ESCRITORA PROFESIONAL}

En una entrevista concedida en 1962 a Ángel Rama, Marta Brunet entrega reveladores antecedentes sobre su vida juvenil en Chillán, antes de que alcanzara notoriedad pública por su primera novela, Montaña adentro (1923). En su conversación con el intelectual uruguayo, la escritora señala que siendo joven había constituido con otros poetas y escritores una especie de ateneo, un grupo dedicado a leer, escribir y publicar sus textos. El dato no es nuevo ${ }^{3}$, lo nuevo es la información que entrega sobre las actividades específicas que ellos desarrollaban. Brunet cuenta que junto a sus amigos hacían recitales, publicaban sus libros, habían conseguido un mecenas (no se menciona su nombre) y contaban con una revista (Ratos ilustrados). Agrega, además, que era la encargada de la distribución de sus productos literarios. Ejerciendo precisamente este rol es como se pone en contacto con Alone, dando inicio a su reconocimiento literario a nivel nacional. Los datos que entrega Brunet dan cuenta de una autora que desde temprano tiene plena conciencia de que el trabajo creativo depende, en buena medida, de la constitución de una mapa cultural activo, en donde las redes de apoyo son fundamentales. Si consideramos que por aquellos años Brunet era una joven que todavía no publicaba su primera novela y que estaba inserta en un entorno provinciano de escasa vida pública y cultural, no deja de sorprender el nivel de actividad que alcanza ese ateneo local y, por sobre todo, el manejo que demostraba la escritora en el establecimiento de redes sociales. Su carta a Alone, presentando a su grupo y la producción del mismo $^{4}$, evidencia que Brunet por ese entonces era capaz de reconocer la existencia de agentes articuladores del campo cultural santiaguino y de entender la importancia de mantener lazos permanentes con los mismos.

Los conocimientos de Brunet sobre el funcionamiento de un espacio cultural indican la familiaridad que tenía la escritora con normas de funcionamiento de un ámbito jerárquico, organizado de acuerdo con ciertas convenciones.

\footnotetext{
En la entrevista a Revista Zig zag, titulada: "Marta Brunet fue calificada inmoral y hereje" de 1961, la autora ya había relatado su pertenencia a este grupo literario en su juventud.

El momento en el que Marta Brunet se pone en contacto por primera vez con Alone para enviarle su novela, Montaña adentro, es relatado por la escritora en la entrevista, "Marta Brunet fue calificada como inmoral y hereje" y también por el propio Alone en el "Prólogo" a las Obras completas de 1963.
} 
Algunos datos biográficos permiten aclarar esta capacidad de Brunet de leer las estructuras internas de las esferas culturales. Hija única de una pareja de emigrantes españoles, Brunet se crío en el confort de una burguesía rural acomodada. Su padre era un comerciante con negocios en Chillán, que adquirió enormes extensiones de terreno en Victoria, lo que le permitió vincularse con las familias terratenientes que controlaban el comercio y la producción agrícola del sur de Chile. La abundancia económica favoreció el acceso de Brunet a una educación privilegiada con institutrices y profesores particulares, y la posibilidad de realizar un viaje a Europa cuando todavía era una adolescente. Además de este capital cultural, Brunet adquirió las normas de sociabilidad que articulaban la vida de la burguesía y las familias tradicionales de provincia: el reconocimiento de las figuras de poder, las formas del trato recatado, las reglas de comportamiento de una señorita de familia pudiente destinada a convertirse en el modelo femenino valorizado en su medio: "una perfecta dueña de casa, marido, niños, cocinar y hacer dulces y conservas para los largos inviernos sureños" ("Con Marta Brunet, Premio Nacional de Literatura" 38).

Brunet, en definitiva, es formada en un habitus en donde las reglas de la docilidad femenina se combinan con un capital cultural ilustrado. En su trayectoria literaria, la autora irá redefiniendo este habitus despojándose de aquellas normas de género de su clase social que la obligaban al rol asistencial de buena ama de casa y le impedían la constitución de su autoría. Sin embargo, este despojo no es total. Brunet elegirá construirse conservando ciertos aspectos de su habitus de clase, reorientándolos de acuerdo a las necesidades y desafíos que se le presentaban. En este marco, Brunet actúa en su esfera letrada reconociendo la existencia de pautas similares a las que operaban en su medio provinciano. Entre ellas, la afirmación de la autoridad masculina y la importancia de las influencias. Estas pautas le serán útiles para generar los lenguajes y las conductas que usará en el campo cultural. Cuando se dirige a Alone en 1923 dando a conocer su ateneo y su obra, lo hace a conciencia que está frente al patrón de la escena letrada santiaguina y que su apoyo la beneficiará. En su entorno pueblerino establecerá las mismas alianzas con figuras prestigiosas cuyas voces son indiscutibles y que pueden, por lo mismo, resguardarla frente a las críticas y posibilitar su trabajo. Reveladora es la anécdota del sacerdote español que avalará su trabajo literario cuando ella acababa de publicar su primera novela. Frente a los cuestionamientos que produjo Montaña adentro entre las familias acomodadas de Chillán, este sacerdote irrumpirá levantado una firme defensa: 
Cuando salió la novela, las señoras beatas de Chillán armaron un lío tremendo, acusándome de inmoral y de hereje. Las niñas de las familias bien recibieron orden de quitarme el saludo. En medio de tanta amargura, hubo un sacerdote español, el padre Nicolás Marín, que salió hidalgamente (¡qué menos en un caballero hispánico!), en mi defensa. Fue a ver a mis consternados padres, y les probó que si yo escribía, era porque estaba poniendo en juego un don de Dios, y que lo incorrecto sería, justamente, poner cortapisas a una vocación que era su mejor regalo ("Marta Brunet fue calificada como inmoral y hereje").

En un interesante análisis a la obra de Brunet y Bombal, la investigadora Rubí Carreño se detiene precisamente en la figura de la autoridad masculina como instancia de poder que arbitrará a favor de las autoras y les permitirá conciliar la escritura con su habitus de género y clase:

Cuando la contradicción entre los textos y la imagen pública se hace muy fuerte, la voz de un hombre respetable resolverá la tensión. Así, en la entrevista 'Marta Brunet fue acusada de inmoral y hereje', Brunet escoge la voz de un religioso para defenderse (45).

A diferencia de María Flora Yáñez, que intentará desarrollar su trayectoria dentro de los límites que le impone su clase y su género, Brunet transgrede $\mathrm{y}$, al mismo tiempo, transa con las normas de su entorno social. No será la buena ama de casa, dedicada a su esposo e hijos, pero tampoco abandonará la tutela masculina, la que le permitirá integrarse a los espacios de producción y circulación literarios. Brunet consigue construir un habitus medianamente flexible que le permite desarrollarse profesionalmente, alcanzar reconocimiento $\mathrm{y}$, al mismo tiempo, seguir representando el papel de mujer formal, eterna señorita educada en un origen acomodado. Ese habitus de origen se convertirá para ella en una caja de herramientas desde donde extraer los lenguajes y conocimientos necesarios que le permitirán hacer redes con varones prestigiosos, con mujeres influyentes en su medio y en muchos casos escapar momentáneamente de las penurias económicas. En efecto, sus columnas en la revista Familia dedicadas a orientar al público femenino en el arte de la decoración doméstica, del buen gusto burgués, o bien sus recetas de cocina que periódicamente aparecen bajo el seudónimo de Hermanita hormiga, nos dan cuenta de una autora que aprovecha inteligentemente su formación para sobrevivir en un nuevo espacio estimulante pero muy inestable. 
La capacidad que tiene Brunet de adaptar su habitus y redefinirlo encuentra explicación en su propio origen burgués. Brunet no nace en el seno una casta familiar tradicional. Su padre fue un rico comerciante español que aprendió a amoldarse a las convenciones sociales y económicas de la nación a la que llegaba. En el ethos de Brunet no estaba la obediencia irrestricta a una cultura y a una identidad, la necesidad de "ser", respetando a como dé lugar una herencia social. Por otra parte, su propia historia personal terminaría afirmando esta flexibilidad en su constitución identitaria. Con la debacle económica de la familia y la necesidad de mantener a una madre que perdía paulatinamente la razón, la autora se verá impulsada a buscar los medios con los que subsistir. Su profesionalismo en gran medida está sujeto a sus constantes necesidades materiales. Es una asalariada de la escritura y su tiempo completo estará dedicado a escribir relatos para revistas nacionales y extranjeras; establecer y fortalecer contactos con figuras influyentes que faciliten trabajos ocasionales y negociar el cobro de sus escritos. En sus cartas podemos ver precisamente la importancia que tiene para ella la falta de recursos. Numerosos son los pasajes en donde comenta el dinero que piensa cobrar por un relato, las conversaciones que ha tenido a fin de obtener un puesto diplomático, las largas horas de espera para que le paguen un cuento y hasta su obsesión por ganar la lotería ${ }^{5}$.

Así como Brunet leyó su campo cultural identificando patrones similares a los que organizaban su habitus social, también fue capaz de ver el lugar que ese campo cultural estaba interesado en asignarle. Alone reconoce que en su primera lectura a Montaña adentro, la novela lo impresionó. Esta era una escritora nueva, que establecía ciertas diferencias con el modelo literario imperante: el criollismo ("La querella del criollismo. Montaña adentro"). Para Alone, Brunet lograba configurar un nuevo criolllismo, alejado del interés por documentar la realidad y, por tanto, diferente de aquellas obras repletas de detalladas descripciones del espacio físico. Según Alone, la literatura de Brunet era una literatura que si bien refería al mundo campesino, lo hacía desde la perspectiva de los personajes. El paisaje rural estaba, en la escritura de la chillaneja, subordinado al carácter de los protagonistas, a sus vaivenes emocionales, a la configuración de sus subjetividades. A pesar de esto, la

$5 \quad$ Las cartas de Marta Brunet a las que me refiero fueron gentilmente facilitadas por el investigador Osvaldo Carvajal, quien encontró este invaluable material epistolar y desarrolla en la actualidad un estudio sobre el mismo. 
literatura de Brunet, se señaló, no era una literatura vanguardista, no aspiraba a desarrollar arriesgados e innovadores cambios estéticos: era una literatura reformista que sin pretensiones lograba superar el anquilosado regionalismo.

Los primeros relatos de Brunet fueron, así, funcionales a los intereses de cierta intelectualidad chilena que por aquellos años promovía cambios en la literatura nacional dentro de una sensibilidad letrada que parecía no estar tan abierta a giros artísticos desestabilizadores de los cánones estéticos. De esta manera la obra de Brunet empezó a ser leída como esa pieza tan esperada que venía a establecer un puente entre lo viejo y lo nuevo. La obra de Brunet era, entonces, un elemento que anunciaba lo que vendría: la vanguardia narrativa.

Esta lectura que hace la crítica a la narrativa de Brunet se siguió manteniendo, con obstinación, aun cuando desde la década del cuarenta en adelante la obra de la autora empezó a acusar un evidente impacto de los lenguajes vanguardistas. En otros términos, Brunet fue estudiada y situada por gran parte de la crítica como una suerte de neo-criollismo, aun cuando sus obras hace bastante tiempo exploraban lenguajes y espacios distintos a los que habían definido su primera etapa narrativa. Esta obstinación de la crítica solo puede ser entendida en el marco de los mismos prejuicios con los que se codificó y ha codificado la literatura de mujeres. En efecto, para un espacio cultural claramente androcéntrico, es mucho más comprensible entender la obra de una escritora vislumbrando un proceso de transformación artística, que constituyendo en sí misma una transformación. En tal sentido, para la escena letrada de esos años Brunet no estaba llamada a realizar los grandes cambios, sino más bien a anunciarlos y ser, en definitiva, una pieza previa (muy previa) en un proceso de reformas estéticas que otros autores deberían culminar.

Brunet nunca puso en duda, problematizó o se distanció explícitamente de los discursos de figuras como Alone. En su forma política de ver y vivir el espacio letrado al que ella deseaba acceder, Alone, como el conjunto de autores y críticos emblemáticos con los que se vinculaba, eran sus aliados. Los costos de este sistema de alianzas pueden llegar a ser altos, y sin duda lo fueron; Brunet hasta hace muy pocos años siguió siendo entendida en los moldes estéticos que definió Alone y su campo intelectual. Sin embargo, en su momento para Brunet los costos pudieron ser mucho más altos aún si se negaba a participar de este tejido de relaciones y lecturas: la negación total de su existencia como escritora.

En definitiva, las diferencias entre Marta Brunet y María Flora Yáñez, con respecto a sus particulares formas de constituir sus trayectorias literarias, 
indican que dar cuenta y analizar la autoría femenina obliga considerar los cruces entre las normas de género sexual y el habitus de clase. La pertenencia a un mismo campo cultural no garantiza la definición de estrategias comunes para alcanzar el reconocimiento como creadoras en las esferas letradas. Estas estrategias se disponen en relación con el campo cultural mismo, pero también al campo social: son las esferas familiares y sociales las que le impondrán los límites y les proveerán de lenguajes y pautas que usarán con distinto éxito en su camino por el posicionamiento autorial. A pesar de sus diferencias, tanto Marta Brunet como María Flora Yáñez tienen algo en común: ambas entienden que la configuración de su autoría pasa, en gran medida, por su capacidad de negociar con el conjunto de normas de clase y género sexual que articulan sus identidades.

\section{BIBLIOGRAFÍA}

Agliati, Carola y Claudia Montero. Albores de modernidad, constitución de sujetos femeninos en Chile, 1900-1920. Santiago: Bicentenario, 2006.

Alone. "La querella del criollismo. Montaña adentro". Revista Zig-zag 2572 (1954): 29. "Prólogo". En Marta Brunet. Obras Completas. Santiago: Zig-zag, 1963.

Amaro, Lorena. "María Flora Yáñez en su escritura autobiográfica: itinerario de un nombre". En Alicia Salomone, Lorena Amaro y Ángela Pérez. Caminos y desvíos: lecturas críticas sobre género y escritura en América Latina. Santiago de Chile: Cuarto Propio, 2010.

Batticuore. Graciela. La mujer romántica. Lectoras, autoras y escritores en la Argentina: 1830-1870. Buenos Aires: Edhasa, 2005.

Bourdieu, Pierre. "El campo literario. Prerrequisitos críticos y principios del método". Revista Criterios 25-28 (1989-1990): 20-40.

Campo del poder y campo intelectual. Buenos Aires: Folios, 1983. 1995.

Las reglas del arte: Génesis y estructura del campo literario. Barcelona: Anagrama,

Brunet, Marta. Obras Completas. Santiago: Zig-zag, 1963.

"Marta Brunet fue calificada como inmoral y hereje". Entrevista a Marta Brunet. Revista Zig-zag 2956 (1961).

"Con Marta Brunet, Premio Nacional de Literatura". Entrevista de Olga Arratia. En viaje 345 (1962): 38.

Carreño Bolívar, Rubí. "Familia y la crisis de los géneros en los años treinta”. Taller de Letras 27 (1999): 135-148.

"Una escena crítica: estereotipos e ideologías de género en la recepción crítica de Marta Brunet y María Luisa Bombal”. Anales de Literatura Chilena 3 (2002): 43-51. 
Catalán, Gonzalo. "Antecedentes sobre la transformación del campo literario en Chile entre 1980-1920”. José Joaquín Brunner y Gonzalo Catalán. Cinco estudios sobre cultura y sociedad. Santiago: Ediciones Ainavillo, 1985.

Doll, Darcie. "Escritoras chilenas de la primera mitad del siglo XX: trayectoria en el campo literario y cultural como criterios para una periodización de su producción". Taller de Letras 2013 (en prensa).

"Desde los salones a la sala de conferencias: mujeres escritoras en el proceso de constitución del campo literario chileno". Revista Chilena de Literatura 71 (2007): 83-100.

Fletcher, Lea. "La profesionalización de la escritora y de sus protagonistas. Argentina, 19001919”. Revista Iberoamericana 206 (2004): 213-224.

Lavrin, Asunción. "Algunas consideraciones finales sobre las tendencias y los temas en la historia de las mujeres latinoamericanas". Las mujeres latinoamericanas. Perspectivas históricas. México: F.C.E., 1985.

López Morales, Berta. "Recepción crítica de la obra de Marta Brunet". Acta literaria 24 (1999): 41-53.

Rama, Ángel. "Literatura y cultura". Transculturación narrativa en América Latina. Montevideo: Arca Editorial, 1989.

La ciudad letrada. Santiago de Chile: Tajamar Editores, 2004.

Sarlo, Beatriz. "Victoria Ocampo o el amor de la cita". La máquina cultural. Maestras. Traductoras y vanguardistas. Buenos Aires: Planeta, 1998. 93-194.

Subercaseaux, Bernardo. Historia del libro en Chile (Alma y cuerpo). Santiago: Lom, 2000. (ed). Inés Echeverría (Iris). Alma femenina y mujer moderna. Antología. Santiago de Chile: Cuarto Propio, 2001.

Valdés, Adriana. "Escritura de mujeres: una pregunta desde Chile". Composición de lugar. Escritos sobre cultura. Santiago de Chile: Universitaria, 1996. 187-214.

Williams, Raymond. Marxismo y Literatura. Barcelona: Ediciones Península, 1980.

Yáñez, María Flora. Historia de mi vida. Santiago de Chile: Nascimento, 1980.

"Contacto con Europa". Atenea 160 (1938): 20-34.

Zanelli, Luisa. Mujeres chilenas de letras. Santiago de Chile: Imprenta Universitaria, 1917. 